\title{
A Public-Participation-Based Mixed Multiattribute Decision-Making Approach for Major Public Affairs
}

\author{
Chenguang Cai $\mathbb{D}^{1},{ }^{1}$ Yong Luo $\mathbb{D}^{2},{ }^{2}$ Guiju Zhu $\mathbb{D}^{3},{ }^{3}$ and Hao Zou $\mathbb{D}^{4}$ \\ ${ }^{1}$ School of Accounting, Hunan University of Finance and Economics, Changsha 410205, China \\ ${ }^{2}$ School of Economics and Management, Sichuan Tourism University, Chengdu 610100, China \\ ${ }^{3}$ School of Management, Hunan University of Technology and Business, Changsha 410205, China \\ ${ }^{4}$ School of Business Administration, Hunan University of Finance and Economics, Changsha 410205, China \\ Correspondence should be addressed to Yong Luo; luoyongcds@163.com
}

Received 14 May 2021; Revised 7 July 2021; Accepted 22 July 2021; Published 9 August 2021

Academic Editor: Ewa Rak

Copyright (c) 2021 Chenguang Cai et al. This is an open access article distributed under the Creative Commons Attribution License, which permits unrestricted use, distribution, and reproduction in any medium, provided the original work is properly cited.

\begin{abstract}
The decision-making activities of major public affairs are closely related to the public, so the decision results of such affairs must be supported by the public. The public must participate in decision-making activities to ensure their effectiveness, which further increases the complexity. In addition, attribute information and public opinion usually present different forms of expression in this type of problem, making decision-making more difficult. Therefore, a suitable decision approach must be chosen to deal with this type of decision problem. This paper addresses the decision-making characteristics of major public affairs and proposes a public-participation-based decision-making approach for mixed multiattribute decision-making problems in major public affairs. The proposed approach can work with entirely unknown attribute weights and decision-making values represented in multiple formats. First, the statistical distribution of public opinions is determined based on the expectation of the attributes, resulting in decision-making reference points for various attributes. The different forms of attributes and reference points are unified. Then, the values of the attributes and reference points are standardized. Afterward, the attribute prospect value for each alternative is calculated using the attribute value and corresponding reference points. The attribute weight intervals are determined based on the importance information of the attributes provided by the public. An optimization model is established to determine the attribute weights to maximize the alternative attribute deviation. Next, the comprehensive prospect value of each alternative is obtained to determine the ranking of the alternatives. Finally, a case analysis is conducted with a method comparison and sensitivity analysis, and the feasibility and effectiveness of the proposed approach are verified. In the proposed method, the reference points for each attribute are set according to the distribution characteristics and ambiguity of public expectations, guaranteeing that public expectations can be effectively reflected in the attribute reference points. In the process of attribute weighting, based on the information for the attribute importance given by the public, the range of attribute weights is determined. Then, we obtain the exact value of the attribute weights using an optimization model to maximize the alternative attribute deviation. The final result of the attribute weights ensures the full expression of public opinion and can improve the differentiation of decision results, which is convenient for ranking alternatives. During evaluation of the alternatives based on prospect theory, the expression forms of attributes and reference points are unified. Subsequently, the values of them are normalized, which satisfy the decision-making requirement of major public affairs.
\end{abstract}

\section{Introduction}

Major public affairs have a profound influence and are closely related to the vital interests of the public. Consequently, they attract a considerable amount of societal attention. Once the public does not support the final decision results, it is easy to generate social risks, leading to a series of social problems $[1,2]$. Numerous public opinions must be gathered across different strata of society to ensure that the decision-making results regarding major public affairs fully reflect the majority public opinion, determining the decision outcomes $[3,4]$. In the process of decision-making, given the 
variations in individual opinions on major public affairs, the distribution of public opinions presents a distinct characteristic of discreteness. In addition, the scale of public opinion is usually immense, which makes it challenging to collect, process, and analyze public opinions. Thus, effective decision-making on major public affairs based on collecting and analyzing public opinions is an important concern for governmental authorities.

The department of public affairs management uses various means to encourage the public to participate in decision-making to ensure that information collected from the public is effective and extensive. Popular public-participation methods include questionnaire surveys, online platform messages, and on-site hearings [5-8]. Some researchers have introduced statistical theory for sorting and analyzing public opinions, identifying representative public opinions based on their statistical distribution characteristics, and providing tools for identifying and processing public opinions [9]. Most citizens lack professional knowledge, making it difficult for them to provide objective guidance and suggestions when contributing to decisionmaking. The opinions they provide focus more on expressing their personal expectations or concerns. In general, the stronger the public expectations or appeals for certain aspects of a topic, the more the attention this aspect needs to receive [10-12]. Therefore, the public expectations should be included in the decision-making of public affairs as an important reference standard for alternative evaluation. It is crucial to set the decision-making reference points effectively based on public expectations. Previous research on decision-making reference points has focused on the effectiveness evaluation of setting reference points [13, 14], the distance measurement between the reference points and alternative attributes [15], and the dynamic evolution characteristics of the reference points [16]. Most existing methods for setting reference points are based on known individual data or a small amount of known data. How to set the reference points based on large amount of public opinions requires further study.

For the decision problems, the results of attribute weight have a great influence on decision-making, so choosing a proper weighting method is necessary for decision-making activities. Common weighting methods include analytic hierarchy process (AHP) [17], entropy weight [18], and maximum deviation methods [19]. In an actual weighting operation process, the attribute weighting methods of decision-making problems are primarily chosen based on several factors: the decision-making problem type, attribute data expression type, distribution characteristics of the attribute data, and others [20, 21]. For decision-making in public affairs, in order to ensure the effectiveness of attribute weighting, the public is introduced to decision-making activities. Public opinions on the importance of the attributes must be considered when determining attribute weights to ensure the effectiveness of attribute weighting. However, the existing attribute weighting approaches are seldom involved in public opinion. Therefore, further research is required on how to effectively weight the attributes considering public opinions.
Different attributes reflect the various contents of each alternative; hence, according to the actual needs of the attribute expression, each attribute is usually expressed in a different form, such as a crisp value, interval value, and linguistic value. For a decision problem, if the attributes are expressed in different forms, we call this decision problem as mixed multiattribute decision problem [22-24]. Public decision-making activities are usually complicated; in order to ensure the effectiveness of the decision, different types of attributes are introduced to explain the decision alternatives. Thus, public decision-making activities usually have the characteristics of mixed multiattribute decision-making problems; the mixed multiattribute characteristics of decision-making problems must be considered when dealing with public decision problems.

In the research regarding decision-making methods, some scholars have introduced fuzzy number operators to decision-making activities, which can provide methodical support for the operation of decision-making information [25-29]. Moreover, some decision methods, such as the Technique for Order of Preference by Similarity to Ideal Solution (TOPSIS) [30], VIekriterijumsko KOmpromisno Rangiranje (VIKOR) method [31], Elimination and Choice Expressing Reality (ELECTRE) method [32, 33], and the prospect theory [34], are widely used in various types of decision problems. Some scholars have used social network analysis to rank schemes based on the relationship and trust between decision-makers $[35,36]$. These research achievements provide necessary technical and methodological support for solving various kinds of decision-making problems.

Major public affairs' decision-making has a high degree of complexity and uncertainty. To ensure decision-making effectiveness, we must consider the actual characteristics of the decision-making problems before the decision method is determined.

According to the above, the existing research can provide necessary references for the study of major public affairs. However, the decision-making problem of major public affairs requires public participation; therefore, the characteristics of public opinions must be considered in the aspects of attribute reference point setting, attribute weighting, and alternative ranking. Relatively, few research achievements exist on public-participation decision-making problems, so further research is needed regarding this aspect. Based on the above analysis, a mixed multiattribute decision-making approach with public participation is proposed in this paper. Compared to the existing research, the contribution of this paper is reflected in the three main aspects.

First, we set attribute reference points based on public expectations. Public expectations have a large volume and high dispersion characteristics, which must be collated and analyzed. In addition, public expectations are subjective and uncertain, making it more challenging to deal with this information. Existing research results rarely consider public expectations when setting reference points, so the existing reference point setting methods are unsuitable for this decision-making background. Based on the above analysis, we propose a reference point setting method considering public 
expectations. We determine the distribution and ambiguity of public expectation according to the expectation information given by the public, and, on this basis, the reference point for each attribute is set.

Second, we propose an attribute weighting method considering public opinions. As we know, the value of attribute weights has a direct effect on the outcomes of decision-making. Existing attribute weighting methods rarely consider public opinion during the decision-making process in major public affairs. To ensure that attribute weighting result is acceptable to the public, we propose an attribute weighting method considering public opinions. In this attribute weighting method, we determine the value range of attribute weights according to public opinion and establish the attribute weighting optimization model to determine the final attribute weights. The result of the attribute weights obtained using this method reflects the public opinion and guarantees the validity of weighting.

Third, we introduce the decision-making method of the prospect theory to rank the alternatives in public-participation scenarios. The prospect theory considers the uncertainty of events and the decision risk and explains the structural effect, preference nonlinearity, resource dependence, risk pursuit, and loss avoidance reflected in people's choices [37]. Therefore, the prospect theory is suitable for the decision-making needs of major public affairs. However, the existing research on the prospect theory is not involved in public-participation scenarios. Thus, the existing decisionmaking method of prospect theory must be improved according to the characteristics of public participation in major public affairs to make it suitable for this type of decision-making problem. Based on the above analysis, we introduce an improved decision-making method of the prospect theory, which requires taking the expectation of public groups as the reference point to guarantee that the decision-making results better reflect public opinion. In the decision-making process, the expression forms of attribute information and public information vary to ensure the implementation of decision-making. Different expression forms of attribute information and public opinions must be unified into an interval before the normalized operation.

The rest of the paper is organized as follows. In Section 2, the preliminaries summarize the knowledge that forms the basis of the paper, and in Section 3, the method and principle are elucidated, explaining the proposed method. Section 4 presents the case analysis to verify the rationality and validity of the approach. In Section 5, a comparison of methods and sensitivity analysis are discussed. Finally, Section 6 provides the conclusions.

\section{Preliminaries}

Definition 1 (see [38]). Given a linguistic set $\mathbf{S}=\left\{s_{0}\right.$, $\left.s_{1}, \ldots, s_{T}\right\}, s_{0}$ and $s_{T}$ are the lower and upper limits of the linguistic variables, respectively. The conversion relationship between the linguistic variables $s_{t}(t=0,1,2, \ldots, T)$ and interval numbers $a_{t}=\left[a_{t}^{L}, a_{t}^{U}\right]$ is as follows, where $0 \leq a_{t}^{L} \leq a_{t}^{U} \leq 1$,

$$
\begin{cases}a_{0}^{L}=0 ; & \\ a_{t}^{U}=a_{t}^{L}+\frac{1}{T}, & 0 \leq t \leq T ; \\ a_{t}^{L}=a_{t-1}^{U}, & 1 \leq t \leq T ; \\ a_{T}^{U}=1 . & \end{cases}
$$

Definition 2. Given the uncertain linguistic variable $s=\left[s_{t_{1}}, s_{t_{2}}\right], \quad s_{t_{1}}, s_{t_{2}} \in \mathbf{S}, \quad$ where $\quad \mathbf{S}=\left\{s_{0}, s_{1}, \ldots, s_{T}\right\}$ $\left(t_{1}, t_{2}=0,1,2, \ldots, T ; 0 \leq t_{1} \leq t_{2} \leq T\right)$. The conversion relationship between the uncertain linguistic variable $s=\left[s_{t_{1}}, s_{t_{2}}\right]$ and interval number $a_{t}=\left[a_{t}^{L}, a_{t}^{U}\right]\left(0 \leq a_{t}^{L} \leq a_{t}^{U} \leq\right.$ 1) is as follows:

$$
\begin{cases}a_{t}^{L}=\frac{t_{1}}{T}, & 0 \leq t_{1} \leq T, \\ a_{t}^{U}=\frac{t_{2}}{T}, & 0 \leq t_{2} \leq T .\end{cases}
$$

Definition 3 (see [39]). Suppose that the interval number $a=\left[a^{L}, a^{U}\right]$ is a nonnegative interval number (i.e., $\left.0 \leq a^{L} \leq a^{U}\right)$; then, the midpoint of $a$ is defined by $\bar{a}=\left(a^{L}+a^{U}\right) / 2$, and the interval number radius of $a$ is defined by $c_{a}=\left(a^{U}-a^{L}\right) / 2$.

\section{Method and Principle}

3.1. Problem Description. The decision-making problems in this study satisfy the following basic assumptions:

(1) The set of alternatives is certain

(2) The set of attributes to describe the alternatives is certain

(3) The expression form of each attribute is known

(4) The public individuals provide expectations based on their psychological perceptions, and the form of expression of public expectations is consistent with the form of expression of the attributes

(5) The public provides the attribute evaluation value of importance in the form of linguistic or uncertain linguistic variables

Suppose that the set of decision-making alternatives for a major public affair is $Z=\left\{z_{1}, z_{2}, \ldots, z_{M}\right\}$ with attribute set $G=\left\{g_{1}, g_{2}, \ldots, g_{N}\right\} \quad$ and attribute weight $\omega=\left(\omega_{1}, \omega_{2}, \ldots, \omega_{N}\right)^{\mathrm{T}}, \sum_{j=1}^{N} \omega_{j}=1$. The value of attribute $j$ in alternative $i$ is $y_{j}^{i}, i=1,2, \ldots, M ; j=1,2, \ldots, N$. Moreover, $y_{j}^{i}$ can be expressed in the form of crisp numbers, interval numbers, linguistic variables, or uncertain linguistic variables. The public provides expectation values and evaluates the importance values of the attributes as per their preferences. Suppose that the number of individuals participating in the evaluation of the expected value of attribute 
$j$ is $H_{j}$. The expected value given by individual $k$ on attribute $j$ is $r_{j}^{k}$, where $k=1,2, \ldots, H_{j}$, which can be in crisp numbers, interval numbers, linguistic variables, or uncertain linguistic variables. Suppose that the number of public individuals participating in evaluating the importance of attribute $j$ is $\zeta_{j}$. The evaluation value of importance provided by public individual $k$ on attribute $j$ is $b_{j}^{k}$, where $k=1,2, \ldots, \zeta_{j}$, which can be in linguistic or uncertain linguistic variables depending on the public's actual need for attribute expression.

The study problem is determining the reference point for each attribute and the attribute weights according to the attribute values for each alternative, the public expected values for each attribute, and the public-evaluated importance value for each attribute. In addition, this study assesses how to choose a practical decision-making approach to rank all alternatives to determine the optimal alternative.

\subsection{Determination of Attribute Reference Points Based on} Public Opinions. The expression form of public expected values is primarily related to two factors: the attribute expression form of the alternative and the accuracy of individual expected values. If the attribute value of the alternative is expressed in real numbers (crisp numbers, interval numbers, etc.), the public expected value of the attribute is also expressed in real numbers (crisp numbers, interval numbers, etc.). In contrast, if the attribute value of the alternative is expressed in linguistic or uncertain linguistic variables, the public expected value of the attribute is also expressed in linguistic or uncertain linguistic variables.

The other factor is the accuracy of the individual expected values. When the public provides their expected values of an attribute, some of the public can express their expected values accurately. Consequently, this portion of the public chooses to provide their expected value of the attribute in crisp numbers or linguistic variables. In contrast, the other portion of the public is affected by internal or external factors and cannot accurately express their expected values for the attributes. This portion of the public usually expresses their expected values in interval numbers or uncertain linguistic variables.

According to the above analysis, the expected values of attributes given by the public also have various forms of expression and thus are expressed in different forms. The expression forms must be normalized to determine the specific distribution and ambiguity of the public expected values and obtain the reference point for each attribute. The reference points for attributes can be determined as follows:

(1) The initial public expected values of the attribute are processed, which is achieved as follows.

Step 1. The public expected values for the attribute from linguistic or uncertain linguistic variables are converted into an interval value using Definitions 1 and 2.

Step 2. The converted public expected values are expressed in crisp or interval numbers. According to Definition 3, if the public individual's expected value, $r_{j}^{k}$, is an interval number, described as $r_{j}^{k}=\left[r_{j}^{k L}, r_{j}^{k U}\right]$, its ambiguity is $c_{j}^{k}=\left(r_{j}^{k U}-r_{j}^{k L}\right) / 2$. If $r_{j}^{k}$ is a crisp number, its ambiguity is $c_{j}^{k}=0$. The comprehensive expected ambiguity is defined as the average expected ambiguity of all public individuals for attribute $j$ (i.e., $\left.c_{j}=\left(1 / H_{j}\right) \sum_{k=1}^{H_{j}} c_{j}^{k}\right)$.

Step 3. Definition 3 converts the interval form of the public individual expected values, $r_{j}^{k}$, into crisp numbers, denoted by $\bar{r}_{j}^{k}$, $\bar{r}_{j}^{k}=\left(r_{j}^{k L}+r_{j}^{k U}\right) / 2$. The crisp form of public expected values, $r_{j}^{k}$, retains the original form, which does not need to be converted. After the conversion operation, the expectation given by individual $k$ on attribute $j$ is a crisp value, defined as $\bar{r}_{j}^{k}$.

(2) Based on the distribution of $\bar{r}_{j}^{k}$, the probability distribution of the expected values on different attributes can be determined. According to a previous study [40], large-scale public opinions usually follow a normal distribution.

(3) The attribute reference points are determined:

Step 1. Under the normal distribution situation for $\bar{r}_{j}^{k}$, the mean of public expectation distribution over $\bar{r}_{j}^{k}$ is defined as $\mu\left(\bar{r}_{j}^{k}\right)$, which can be determined based on the distribution of $\bar{r}_{j}^{k}$. The distribution variance of the public expected value on attribute $j$ is defined as $\sigma\left(\bar{r}_{j}^{k}\right)$.

Step 2. The attribute reference point $\widetilde{r}_{j}^{*}$ is confirmed, which is expressed in the form of interval numbers:

$\widetilde{r}_{j}^{*}=\left[\widetilde{r}_{j}^{* L}, \tilde{r}_{j}^{* U}\right]=\left[\mu\left(\bar{r}_{j}^{k}\right)-c_{j}, \mu\left(\bar{r}_{j}^{k}\right)+c_{j}\right]$. The attribute reference point $\tilde{r}_{j}^{*}$ can be determined using the mean of public expectation distribution $\mu\left(\bar{r}_{j}^{k}\right)$ and the comprehensive ambiguity of the public expected values $c_{j}$.

\subsection{Calculation of the Alternative Prospect Value}

3.3.1. Normalization of the Attribute Values and Reference Points. According to Section 3.2, the finalized form of the attribute reference point is an interval number, whereas the attribute value of the alternative can be expressed as a crisp number, interval number, linguistic variable, or uncertain linguistic variable. The dimensions of various attributes are inconsistent, so the attribute values and reference points of all alternatives must be normalized.

The attribute values are unified in the form of interval numbers. If the attribute value of the alternative is a crisp number, it is rewritten as an interval number with equal upper and lower limits. If the attribute value of the alternative is a linguistic or uncertain linguistic variable, then Definitions 1 and 2 can convert it into an interval number. The interval form of $y_{j}^{i}$ is defined as $y_{j}^{i}=\left[y_{j}^{i L}, y_{j}^{i U}\right]$. 
Next, the attribute values and attribute reference points are normalized. Equations (3)-(6) are used to normalize the attribute values and reference points in interval numbers to eliminate the dimension influence of the original data. The normalized attribute value of $y_{j}^{i}$ is $p_{i j}=\left[p_{i j}^{L}, p_{i j}^{U}\right], 0 \leq p_{i j}^{L} \leq p_{i j}^{U} \leq 1$, and the normalized attribute reference point of $\widetilde{r}_{j}^{*}$ is $q_{j}=\left[q_{j}^{L}, q_{j}^{U}\right], 0 \leq q_{j}^{L} \leq q_{j}^{U} \leq 1$.

Attribute $g_{j}$ is a profit index:

$$
\begin{aligned}
& \left\{\begin{array}{l}
p_{i j}^{L}=\frac{y_{j}^{i L}-\min \left\{\min _{1 \leq i \leq M}\left\{y_{j}^{i L}\right\}, \widetilde{r}_{j}^{* L}\right\}}{\max \left\{\max _{1 \leq i \leq M}\left\{y_{j}^{i U}\right\}, \widetilde{r}_{j}^{* U}\right\}-\min \left\{\min _{1 \leq i \leq M}\left\{y_{j}^{i L}\right\}, \widetilde{r}_{j}^{* L}\right\}}, \\
p_{i j}^{U}=\frac{y_{j}^{i U}-\min \left\{\min _{1 \leq i \leq M}\left\{y_{j}^{i L}\right\}, \widetilde{r}_{j}^{* L}\right\}}{\max \left\{\max _{1 \leq i \leq M}\left\{y_{j}^{i U}\right\}, \widetilde{r}_{j}^{* U}\right\}-\min \left\{\min _{1 \leq i \leq M}\left\{y_{j}^{i L}\right\}, \widetilde{r}_{j}^{* L}\right\}},
\end{array}\right. \\
& \left\{\begin{array}{l}
q_{j}^{L}=\frac{\widetilde{r}_{j}^{* L}-\min \left\{\min _{1 \leq i \leq M}\left\{y_{j}^{i L}\right\}, \widetilde{r}_{j}^{* L}\right\}}{\max \left\{\max _{1 \leq i \leq M}\left\{y_{j}^{i U}\right\}, \widetilde{r}_{j}^{* U}\right\}-\min \left\{\min _{1 \leq i \leq M}\left\{y_{j}^{i L}\right\}, \widetilde{r}_{j}^{* L}\right\}}, \\
q_{j}^{U}=\frac{\widetilde{r}_{j}^{* U}-\min \left\{\min _{1 \leq i \leq M}\left\{y_{j}^{i L}\right\}, \tilde{r}_{j}^{* L}\right\}}{\max \left\{\max _{1 \leq i \leq M}\left\{y_{j}^{i U}\right\}, \widetilde{r}_{j}^{* U}\right\}-\min \left\{\min _{1 \leq i \leq M}\left\{y_{j}^{i L}\right\}, \widetilde{r}_{j}^{* L}\right\}} .
\end{array}\right.
\end{aligned}
$$

In addition, attribute $g_{j}$ is a cost index:

$$
\begin{aligned}
& \left\{\begin{array}{l}
p_{i j}^{L}=\frac{\max \left\{\max _{1 \leq i \leq M}\left\{y_{j}^{i U}\right\}, \widetilde{r}_{j}^{* U}\right\}-y_{j}^{i U}}{\max \left\{\max _{1 \leq i \leq M}\left\{y_{j}^{i U}\right\}, \widetilde{r}_{j}^{* U}\right\}-\min \left\{\min _{1 \leq i \leq M}\left\{y_{j}^{i L}\right\}, \widetilde{r}_{j}^{* L}\right\}}, \\
p_{i j}^{U}=\frac{\max \left\{\max _{1 \leq i \leq M}\left\{y_{j}^{i U}\right\}, \widetilde{r}_{j}^{* U}\right\}-y_{j}^{i L}}{\max \left\{\max _{1 \leq i \leq M}\left\{y_{j}^{i U}\right\}, \widetilde{r}_{j}^{* U}\right\}-\min \left\{\min _{1 \leq i \leq M}\left\{y_{j}^{i L}\right\}, \widetilde{r}_{j}^{* L}\right\}},
\end{array}\right. \\
& \left\{\begin{array}{l}
q_{j}^{L}=\frac{\max \left\{\max _{1 \leq i \leq M}\left\{y_{j}^{i U}\right\}, \widetilde{r}_{j}^{* U}\right\}-\widetilde{r}_{j}^{* U}}{\max \left\{\max _{1 \leq i \leq M}\left\{y_{j}^{i U}\right\}, \widetilde{r}_{j}^{* U}\right\}-\min \left\{\min _{1 \leq i \leq M}\left\{y_{j}^{i L}\right\}, \widetilde{r}_{j}^{* L}\right\}}, \\
q_{j}^{U}=\frac{\max \left\{\max _{1 \leq i \leq M}\left\{y_{j}^{i U}\right\}, \widetilde{r}_{j}^{* U}\right\}-\widetilde{r}_{j}^{* L}}{\max \left\{\max _{1 \leq i \leq M}\left\{y_{j}^{i U}\right\}, \widetilde{r}_{j}^{* U}\right\}-\min \left\{\min _{1 \leq i \leq M}\left\{y_{j}^{i L}\right\}, \widetilde{r}_{j}^{* L}\right\}} .
\end{array}\right.
\end{aligned}
$$

3.3.2. Calculation of Prospect Profit and Loss Value over Different Attributes. The profit, $G_{i j}$, and loss, $F_{i j}$, of attribute value $p_{i j}$ are calculated according to the relationship between the normalized attribute value, $p_{i j}$, and the normalized reference point, $q_{j}$. The equations to calculate $G_{i j}$ and $F_{i j}$ are presented in Table 1 . The values of $v_{i j}^{(+)}$and $v_{i j}^{(-)}$ are determined based on the prospect theory, as given in equation (7). According to a previous study [41], the coefficients of $\alpha, \beta, \lambda$ are $\alpha=\beta=0.88$ and $\lambda=2.25$ :

$$
\begin{cases}v_{i j}^{(+)}=\left(G_{i j}\right)^{\alpha}, & G_{i j} \geq 0, \\ v_{i j}^{(-)}=-\lambda\left(-F_{i j}\right)^{\beta}, & F_{i j}<0 .\end{cases}
$$

The prospect profit-loss matrix of the attribute can be constructed as follows: $\mathrm{VM}=\left[v_{i j}\right]_{M \times N}$, where the value of $v_{i j}$ can be obtained using the following equation:

$$
v_{i j}=v_{i j}^{(+)}+v_{i j}^{(-)} \text {. }
$$

3.4. Determination of Attribute Weights. First, the public evaluation information of the attribute importance is processed. Public individuals give their evaluation values of the importance of different attributes in the form of linguistic or uncertain linguistic variables. Some individuals can express their opinions more accurately, so they choose to evaluate them in linguistic variables. Others feel a certain degree of ambiguity or uncertainty over the evaluation results of their 
TABle 1: Equations to calculate $G_{i j}$ and $F_{i j}$.

\begin{tabular}{lccc}
\hline No. & The relationship between $p_{i j}$ and $q_{j}$ & The loss $F_{i j}$ & The profit $G_{i j}$ \\
\hline 1 & $p_{i j}^{U}<q_{j}^{L}$ & $0.5\left(p_{i j}^{L}+p_{i j}^{U}\right)-q_{j}^{L}$ & 0 \\
\hline 2 & $q_{j}^{U}<p_{i j}^{L}$ & 0 & $0.5\left(p_{i j}^{L}+p_{i j}^{U}\right)-q_{j}^{U}$ \\
\hline 3 & $p_{i j}^{L}<q_{j}^{L} \leq p_{i j}^{U}<q_{j}^{U}$ & 0 \\
\hline 4 & $q_{j}^{L}<p_{i j}^{L} \leq q_{j}^{U}<p_{i j}^{U}$ & $0.5\left(p_{i j}^{L}-q_{j}^{L}\right)$ & $0.5\left(p_{i j}^{U}-q_{j}^{U}\right)$ \\
\hline 5 & $p_{i j}^{L}<q_{j}^{L}<q_{j}^{U}<p_{i j}^{U}$ & 0 & $0.5\left(p_{i j}^{U}-q_{j}^{U}\right)$ \\
\hline 6 & $q_{j}^{L} \leq p_{i j}^{L}<p_{i j}^{U} \leq q_{j}^{U}$ & $0.5\left(p_{i j}^{L}-q_{j}^{L}\right)$ & 0 \\
\hline
\end{tabular}

given attribute importance, so they choose to express their opinions using uncertain linguistic variables. According to the expression characteristics of the public, Definitions 1 and 2 can be used to convert the public evaluation values from linguistic or uncertain linguistic variables into interval numbers. If the number of individuals participating in the importance evaluation of attribute $j$ is $\zeta_{j}$, the importance evaluation value given by individual $k$ over attribute $j$ is $\varepsilon_{j}^{k}, k=1,2, \ldots, \zeta_{j}$. Based on Definitions 1 and $2, \varepsilon_{j}^{k}$ can be converted into the interval type $b_{j}^{k}=\left[b_{j}^{k L}, b_{j}^{k U}\right]$, $k=1,2, \ldots, \zeta_{j}$. We take the average value of the importance evaluation of the public on attribute $j$ as the comprehensive importance evaluation value of attribute $j$ (i.e., $b_{j}=\left[b_{j}^{L}, b_{j}^{U}\right]$, where $b_{j}^{L}=\left(1 / \zeta_{j}\right) \sum_{k=1}^{\zeta_{j}} b_{k}^{k L}, b_{j}^{U}=\left(1 / \zeta_{j}\right) \sum_{k=1}^{\zeta_{j}} b_{k}^{k U}, \quad 0 \leq b_{j}^{L} \leq$ $\left.b_{j}^{U} \leq 1\right)$.

Second, the value range of the attribute weights $\omega_{j}$ is determined. The value range of the attribute weights $\omega_{j}$ is assumed to be $\omega_{j} \in\left[\omega_{j}^{L}, \omega_{j}^{U}\right]$. Based on the public comprehensive evaluation value of the importance over attribute $j$, the upper and lower limits of $\omega_{j}$ are determined:

$$
\left\{\begin{array}{l}
\omega_{j}^{L}=\frac{b_{j}^{L}}{b_{j}^{L}+\sum_{e=1, e \neq j}^{N-1} b_{e}^{U}}, \\
\omega_{j}^{U}=\frac{b_{j}^{U}}{b_{j}^{U}+\sum_{e=1, e \neq j}^{N-1} b_{e}^{L}} .
\end{array}\right.
$$

Theorem 1. For $\omega_{j} \in\left[\omega_{j}^{L}, \omega_{j}^{U}\right], \omega_{j}$ must exist that meets the constraints of $0 \leq \omega_{j} \leq 1$ and $\sum_{j=1}^{N} \omega_{j}=1$.

Proof. Because $0 \leq b_{j}^{L} \leq\left(b_{j}^{L}+\sum_{e=1, e \neq j}^{N-1} b_{e}^{U}\right) \quad$ and $0 \leq b_{j}^{U} \leq\left(b_{j}^{U}+\sum_{e=1, e \neq j}^{N-1} b_{e}^{L}\right), 0 \leq\left(b_{j}^{L} /\left(b_{j}^{L}+\sum_{e=1, e \neq j}^{N-1} b_{e}^{U}\right)\right) \leq 1$ and $0 \leq\left(b_{j}^{U} /\left(b_{j}^{U}+\sum_{e=1, e \neq j}^{N-1} b_{e}^{L}\right)\right) \leq 1$. Thus, it can be deduced that $0 \leq \omega_{j} \leq 1$. As $0 \leq b_{j}^{L} \leq b_{j}^{U} \leq 1$ and $\omega_{j}^{L}=\left(b_{j}^{L} /\left(b_{j}^{L}+\sum_{e=1, e \neq j}^{N-1}\right.\right.$ $\left.\left.b_{e}^{U}\right)\right) \leq\left(b_{j}^{L} / \sum_{j=1}^{N} b_{j}^{L}\right)$, and it can be deduced that $\left(\sum_{j=1}^{N} \omega_{j}^{L}=\right.$ $\left.\sum_{j=1}^{N}\left[b_{j}^{L} /\left(b_{j}^{L}+\sum_{e=1, e \neq j}^{N-1} b_{e}^{U}\right)\right]\right) \leq \sum_{j=1}^{N}\left(b_{j}^{L} / \sum_{j=1}^{N} b_{j}^{L}\right)=1$. Similarly, it is deduced that $\sum_{j=1}^{N} \omega_{j}^{U} \geq 1$. As the value of $\omega_{j}$ is continuous within the range $\left[\omega_{j}^{L}, \omega_{j}^{U}\right]$ and $0 \leq \omega_{j}^{L} \leq \omega_{j}^{U} \leq 1$, so $\sum_{j=1}^{N} \omega_{j}=1$ must exist.

Third, we determine the attribute weights. An optimization model is constructed to solve the attribute weights to maximize the dispersion of attributes on all alternatives:

$$
\begin{aligned}
& \max \psi\left(\omega_{j}\right)=\frac{1}{M} \sum_{i=1}^{M} \sum_{j=1}^{N}\left(\frac{\left|p_{i j}^{L}-\tilde{p}_{j}^{L}\right|+\left|p_{i j}^{U}-\widetilde{p}_{j}^{U}\right|}{2}\right) \omega_{j} \\
& \text { s.t. }\left\{\begin{array}{l}
\omega_{j}^{L} \leq \omega_{j} \leq \omega_{j}^{U} \\
\sum_{j=1}^{N} \omega_{j}=1 \\
\tilde{p}_{j}=\left[\tilde{p}_{j}^{L}, \tilde{p}_{j}^{U}\right]=\left[\frac{1}{M} \sum_{i=1}^{M} p_{i j}^{L}, \frac{1}{M} \sum_{i=1}^{M} p_{i j}^{U}\right] .
\end{array}\right.
\end{aligned}
$$


Theorem 2. Model (10) must have an optimal solution.

Proof. Under the constraint $\omega_{j} \in\left[\omega_{j}^{L}, \omega_{j}^{U}\right]$, there must be a reasonable value of $\omega_{j}$ that satisfies $\sum_{j=1}^{N} \omega_{j}=1$, so the feasible domain of the attribute weight is a nonempty set. In addition, $0 \leq p_{i j} \leq 1$ and $0 \leq p_{j} \leq 1$, so it is easy to deduce that $0 \leq\left(\left(\left|p_{i j}^{L}-p_{j}^{L}\right|+\left|p_{i j}^{U}-p_{j}^{U}\right|\right) / 2\right) \leq 1$. As known, $0 \leq \omega_{j} \leq 1, \quad \sum_{j=1}^{N} \omega_{j}=1$; thus, it can be deduced that $0 \leq \sum_{j=1}^{N}\left(\left(\left|p_{i j}^{L}-p_{j}^{L}\right|+\left|p_{i j}^{U}-p_{j}^{U}\right|\right) / 2\right) \omega_{j} \leq 1$ and $0 \leq$ $\psi\left(\omega_{j}\right)=(1 / M) \sum_{i=1}^{M} \sum_{j=1}^{N}\left(\left(\left|p_{i j}^{L}-\widetilde{p}_{j}^{L}\right|+\left|p_{i j}^{U}-\widetilde{p}_{j}^{U}\right|\right) / 2\right) \omega_{j} \leq 1$. As $\psi\left(\omega_{j}\right)$ is a bounded continuous function, the constraint condition of the attribute weight is a bounded closed set, so Model (10) must have an optimal solution.

To sum up, the specific steps of the proposed decisionmaking approach are as follows:

Step 1. The public expected values of attributes with various expressions are converted into crisp numbers.

Step 2. The distribution of the public expected values is determined on all attributes according to the public expected opinion in the crisp number type. Next, the attribute reference points are obtained based on the distribution mean of the public expectation and comprehensive ambiguity of public expected values.

Step 3. The attribute value and reference points are normalized. The attribute prospect value of each alternative is calculated based on the prospect theory.

Step 4. The value range of the attribute weights is determined using equation (9) and Model (10) to determine the attribute weight.

Step 5. The comprehensive prospect values of different alternatives are obtained using equation (11) to realize the ranking of alternative alternatives:

$$
V_{i}=\sum_{j=1}^{N} \omega_{j} v_{i j} .
$$

\section{Case Analysis}

We take a subway construction project as an example to verify the rationality and effectiveness of the method proposed in this paper. A provincial capital city plans to extend the No. 2 subway line to the west, for which three alternatives can be selected. The extension of the subway line will make public transportation more convenient for residents along the line. However, the subway construction will take a long time to be completed, occupy a large amount of public space, and generate substantial dust, which interferes with the daily life of the surrounding residents. According to the construction requirements and characteristics of the subway line, the organizers of the decision-making activity selected four attributes to evaluate the alternatives: the average distance between the stations and densely populated areas along the line ( $g_{1}$, units: $m$, cost-based index), estimated construction time ( $g_{2}$, units: month, cost-based index), enclosed public area for construction $\left(g_{3}\right.$, units: $\mathrm{m}^{2}$, costbased index), and dust and sand treatment effect $\left(g_{4}\right.$, qualitative index, profit-based index). Among these alternatives, $g_{1}$ is expressed in crisp numbers, $g_{2}$ and $g_{3}$ are expressed in interval numbers, and $g_{4}$ is expressed in linguistic or uncertain linguistic variables. The conversion standard between the dust and sand treatment effect and linguistic variables is presented in Table 2, and the attribute values of different alternatives are listed in Table 3.

The primary public group affected by the construction and operation of the subway is urban residents. Therefore, during the decision-making process, the opinions of the public group directly affected by the subway must be fully considered. Various media-driven methods were used to publicize the project to enable the public to understand the actual subway project situation better. The public could express their opinions on the subway project using different methods, such as online platforms, telephone, and mail questionnaires. The public provides two pieces of evaluation information based on their opinions of the attributes: their expectations and the importance evaluation value. The conversion standard between the evaluation values of the importance and linguistic variables is given in Table 2.

When the public opinion survey was finished, the organizers of the public opinion survey identified and counted the public individuals who effectively participated. The statistical results of the public expectations are listed in Table 4, and the statistical results of the public importance evaluation values of different attributes are presented in Table 5. Numerous individuals participated in the survey effectively. Due to the space limitations of the article, we only present the partial statistical results of the public opinions in Tables 4 and 5 .

The original public expected values of the attributes in Table 4 were processed. First, the public expected values of the attributes were converted into interval numbers. Next, the comprehensive ambiguity of the expected values of the attributes was calculated which was shown in Table 4 . Then, the public expected values of the attributes in interval numbers were converted into crisp numbers in Definition 3; the details of the public expected values for different attributes in the form of crisp numbers are shown in Table 6.

Finally, based on the relevant content in Table 6 , the distribution of public expected values for various attributes was examined. The distribution of public expected values on various attributes was examined. The fittings of the distributions are illustrated in Figures 1-4. According to the statistical distribution results and comprehensive ambiguity of the public expected values, the reference point of each attribute was determined, as presented in Table 7.

Equations (3)-(6) were used to normalize the attribute reference points and attribute values of different alternatives. The normalized attribute reference points and alternative attribute values are listed in Table 8 .

Next, equations (7) and (8) were used to calculate the prospect values of the attributes, and the prospect profit-loss matrix of the attributes is expressed: 
TABLE 2: Conversion standards between dust and sand treatment (attribute importance) and linguistic variables.

\begin{tabular}{|c|c|c|c|c|c|}
\hline $\begin{array}{l}\text { Dust and sand treatment } \\
\text { effect (attribute importance) }\end{array}$ & $\begin{array}{l}\text { Extremely poor (can } \\
\text { be ignored) }\end{array}$ & $\begin{array}{l}\text { Terribly poor } \\
\text { (extremely } \\
\text { unimportant) }\end{array}$ & $\begin{array}{l}\text { Very poor (very } \\
\text { unimportant) }\end{array}$ & Poor (unimportant) & $\begin{array}{l}\text { Fair } \\
\text { (good) }\end{array}$ \\
\hline Linguistic variable & $s_{0}$ & $s_{1}$ & $s_{2}$ & $s_{3}$ & $s_{4}$ \\
\hline $\begin{array}{l}\text { Dust and sand treatment } \\
\text { effect (attribute importance) }\end{array}$ & Good (important) & $\begin{array}{l}\text { Very good (very } \\
\text { important) }\end{array}$ & $\begin{array}{c}\text { Extremely good } \\
\text { (extremely important) }\end{array}$ & $\begin{array}{l}\text { Perfect (maximum } \\
\text { importance) }\end{array}$ & - \\
\hline Linguistic variable & $s_{5}$ & $s_{6}$ & $s_{7}$ & $s_{8}$ & - \\
\hline
\end{tabular}

TABLE 3: Attribute values of various alternatives.

\begin{tabular}{lcccc}
\hline Alternatives & $\begin{array}{c}\text { Average distance between the station } \\
\text { and the population gathering } \\
\text { area along the line }(\mathrm{m})\end{array}$ & $\begin{array}{c}\text { Estimated construction } \\
\text { time of the } \\
\text { project }(\mathrm{months})\end{array}$ & $\begin{array}{c}\text { Construction enclosed } \\
\text { public areas }\left(\mathrm{m}^{2}\right)\end{array}$ & $\begin{array}{c}\text { Dust and sand } \\
\text { treatment } \\
\text { effect }(\text { qualitative index) }\end{array}$ \\
\hline 1 & 330 & {$[64,71]$} & {$[28732,29849]$} & {$\left[S_{6}, S_{7}\right]$} \\
2 & 379 & {$[61,65]$} & {$[25373,27711]$} & $S_{7}$ \\
3 & 336 & {$[64,68]$} & {$[28064,29849]$} & {$\left[S_{6}, S_{7}\right]$} \\
\hline
\end{tabular}

TABLe 4: Statistics of public expected values for different attributes.

\begin{tabular}{|c|c|c|c|c|c|c|c|c|c|c|c|}
\hline \multirow{2}{*}{\multicolumn{3}{|c|}{$\begin{array}{l}\text { Average distance between the } \\
\text { station and the population } \\
\text { gathering area along the line }(\mathrm{m}) \\
\text { Number of effective participants }\end{array}$}} & \multicolumn{3}{|c|}{$\begin{array}{l}\text { Estimated construction time of } \\
\text { the project (months) }\end{array}$} & \multicolumn{3}{|c|}{$\begin{array}{l}\text { Construction-enclosed public } \\
\text { areas }\left(\mathrm{m}^{2}\right)\end{array}$} & \multicolumn{3}{|c|}{$\begin{array}{l}\text { Dust and sand treatment effect } \\
\text { (qualitative index) }\end{array}$} \\
\hline & & & \multicolumn{3}{|c|}{ Number of effective participants } & \multicolumn{3}{|c|}{ Number of effective participants } & \multicolumn{3}{|c|}{ Number of effective participant } \\
\hline \multicolumn{3}{|c|}{5472} & \multicolumn{3}{|c|}{6070} & \multicolumn{3}{|c|}{5518} & \multicolumn{3}{|c|}{5491} \\
\hline No. & $\begin{array}{l}\text { Expected } \\
\text { values }\end{array}$ & Ambiguity & No. & $\begin{array}{l}\text { Expected } \\
\text { value }\end{array}$ & Ambiguity & No. & $\begin{array}{l}\text { Expected } \\
\text { value }\end{array}$ & Ambiguity & No. & $\begin{array}{l}\text { Expected } \\
\text { value }\end{array}$ & Ambiguity \\
\hline 1 & {$[453,499]$} & 23 & 1 & {$[55,58]$} & 1.5 & 1 & $\begin{array}{l}\text { [30528, } \\
30789]\end{array}$ & 130.5 & 1 & {$\left[S_{4}, S_{5}\right]$} & 0.0625 \\
\hline 2 & {$[377,377]$} & 0 & 2 & {$[64,66]$} & 1 & 2 & $\begin{array}{l}{[26212,} \\
29284]\end{array}$ & 1536 & 2 & {$\left[S_{5}, S_{5}\right]$} & 0 \\
\hline$\cdots$ & $\cdots$ & $\cdots$ & $\cdots$ & $\cdots$ & $\cdots$ & $\cdots$ & $\cdots$ & $\cdots$ & $\cdots$ & $\cdots$ & $\cdots$ \\
\hline 5471 & {$[346,352]$} & 3 & 6069 & {$[67,74]$} & 3.5 & 5517 & $\begin{array}{l}{[30049,} \\
33846]\end{array}$ & 1898.5 & 5490 & {$\left[S_{5}, S_{6}\right]$} & 0.0625 \\
\hline 5472 & {$[338,374]$} & 18 & 6070 & {$[70,78]$} & 4 & 5518 & $\begin{array}{l}{[28175,} \\
31285]\end{array}$ & 1555 & 5491 & {$\left[S_{6}, S_{6}\right]$} & 0 \\
\hline
\end{tabular}

Table 5: Public evaluation results of the importance for different attributes.

\begin{tabular}{|c|c|c|c|c|c|c|c|}
\hline \multicolumn{2}{|c|}{$\begin{array}{l}\text { Average distance between } \\
\text { the station and the } \\
\text { population gathering area } \\
\text { along the line }(\mathrm{m})\end{array}$} & \multicolumn{2}{|c|}{$\begin{array}{l}\text { Estimated construction } \\
\text { time of the project } \\
\text { (months) }\end{array}$} & \multicolumn{2}{|c|}{$\begin{array}{l}\text { Construction-enclosed } \\
\text { public areas }\left(\mathrm{m}^{2}\right)\end{array}$} & \multicolumn{2}{|c|}{$\begin{array}{l}\text { Dust and sand treatment } \\
\text { effect (qualitative index) }\end{array}$} \\
\hline \multicolumn{2}{|c|}{$\begin{array}{l}\text { Number of effective } \\
\text { participants }\end{array}$} & \multicolumn{2}{|c|}{$\begin{array}{c}\text { Number of effective } \\
\text { participants }\end{array}$} & \multicolumn{2}{|c|}{$\begin{array}{c}\text { Number of effective } \\
\text { participants }\end{array}$} & \multicolumn{2}{|c|}{$\begin{array}{l}\text { Number of effective } \\
\text { participants }\end{array}$} \\
\hline \multicolumn{2}{|c|}{4186} & \multicolumn{2}{|c|}{4182} & \multicolumn{2}{|c|}{4186} & \multicolumn{2}{|c|}{4185} \\
\hline No. & Importance & No. & Importance & No. & Importance & No. & Importance \\
\hline 1 & {$\left[S_{3}, S_{4}\right]$} & 1 & {$\left[S_{1}, S_{2}\right]$} & 1 & {$\left[S_{3}, S_{3}\right]$} & 1 & {$\left[S_{3}, S_{5}\right]$} \\
\hline 2 & {$\left[S_{3}, S_{4}\right]$} & 2 & {$\left[S_{1}, S_{2}\right]$} & 2 & {$\left[S_{3}, S_{3}\right]$} & 2 & {$\left[S_{3}, S_{5}\right]$} \\
\hline $\begin{array}{l}\cdots \\
4185\end{array}$ & {$\left[S_{3}, S_{6}\right]$} & $\begin{array}{c}\cdots \\
4181\end{array}$ & {$\left[\begin{array}{c}\cdots \\
{\left[S_{2}, S_{2}\right]}\end{array}\right.$} & $\begin{array}{c}\cdots \\
4185\end{array}$ & {$\left[S_{1}, S_{4}\right]$} & $\begin{array}{c}\cdots \\
4184\end{array}$ & {$\left[\begin{array}{c}\cdots \\
{\left[S_{4}, S_{5}\right]}\end{array}\right.$} \\
\hline 4186 & {$\left[S_{3}, S_{6}\right]$} & 4182 & {$\left[S_{0}, S_{1}\right]$} & 4186 & {$\left[S_{1}, S_{4}\right]$} & 4185 & {$\left[S_{4}, S_{5}\right]$} \\
\hline
\end{tabular}


TABLe 6: The public expected values for different attributes in the form of crisp numbers.

\begin{tabular}{|c|c|c|c|c|c|c|c|}
\hline \multicolumn{2}{|c|}{$\begin{array}{l}\text { Average distance between } \\
\text { the station and the } \\
\text { population gathering area } \\
\text { along the line }(\mathrm{m})\end{array}$} & \multicolumn{2}{|c|}{$\begin{array}{l}\text { Estimated construction time } \\
\text { of the project (months) }\end{array}$} & \multicolumn{2}{|c|}{$\begin{array}{l}\text { Construction-enclosed } \\
\text { public areas }\left(\mathrm{m}^{2}\right)\end{array}$} & \multicolumn{2}{|c|}{$\begin{array}{l}\text { Dust and sand treatment } \\
\text { effect (qualitative index) }\end{array}$} \\
\hline No. & Expected value & No. & Expected value & No. & Expected value & No. & Expected value \\
\hline 1 & 476 & 1 & 56 & 1 & 30658.5 & 1 & 0.5625 \\
\hline 2 & 377 & 2 & 65 & 2 & 27748 & 2 & 0.5000 \\
\hline$\ldots$ & $\ldots$ & $\ldots$ & $\ldots$ & $\ldots$ & $\ldots$ & $\ldots$ & $\ldots$ \\
\hline 5471 & 349 & 6069 & 70.5 & 5517 & 31947.5 & 5490 & 0.6875 \\
\hline 5472 & 356 & 6070 & 74 & 5518 & 29730 & 5491 & 0.7500 \\
\hline
\end{tabular}

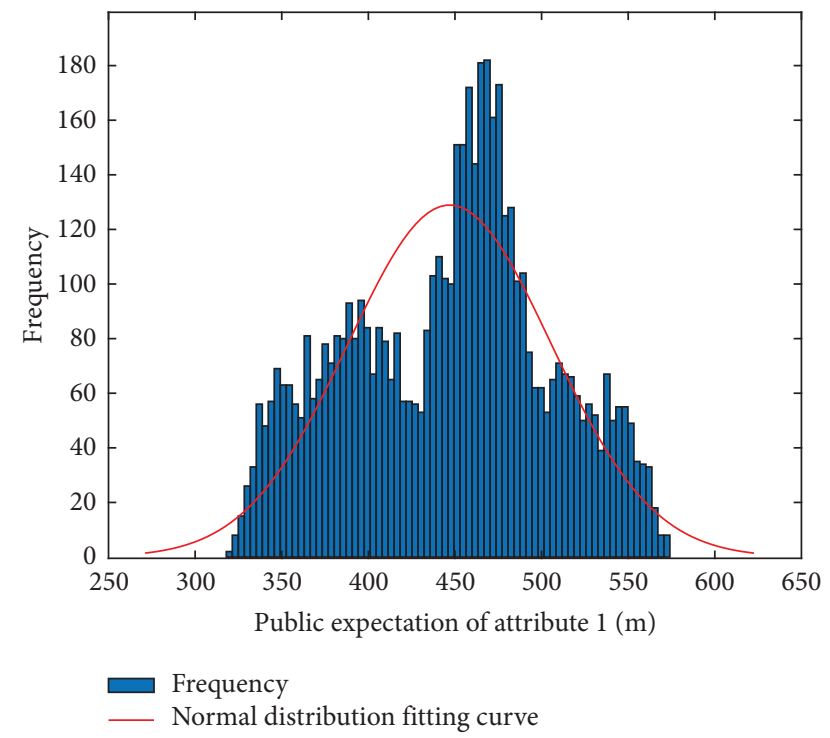

FIGURE 1: Fitting curve for public expected values of attribute 1.

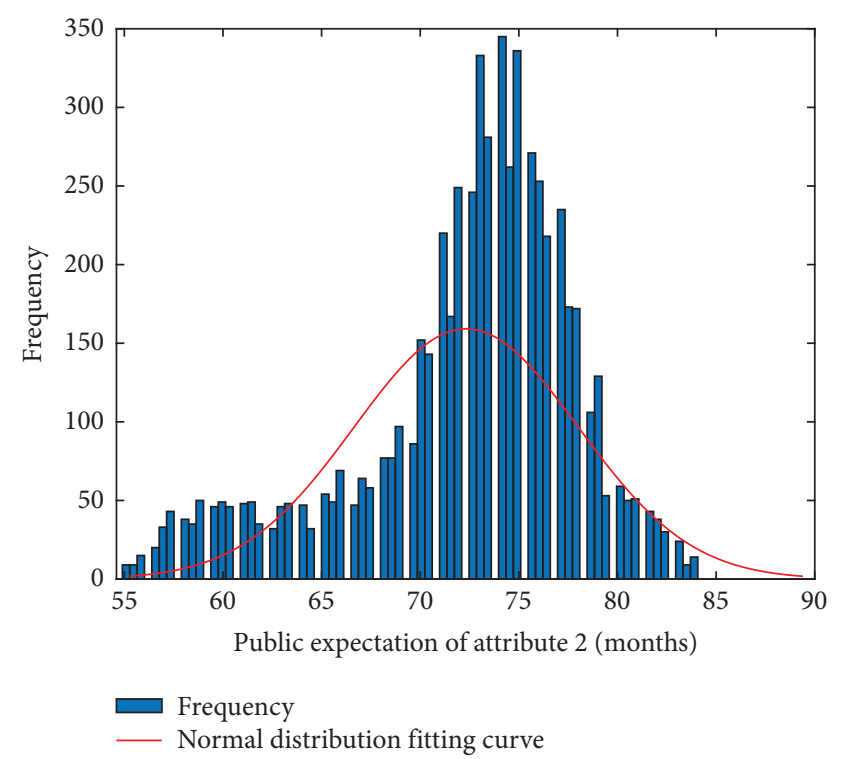

FIgURE 2: Fitting curve for public expected values of attribute 2.

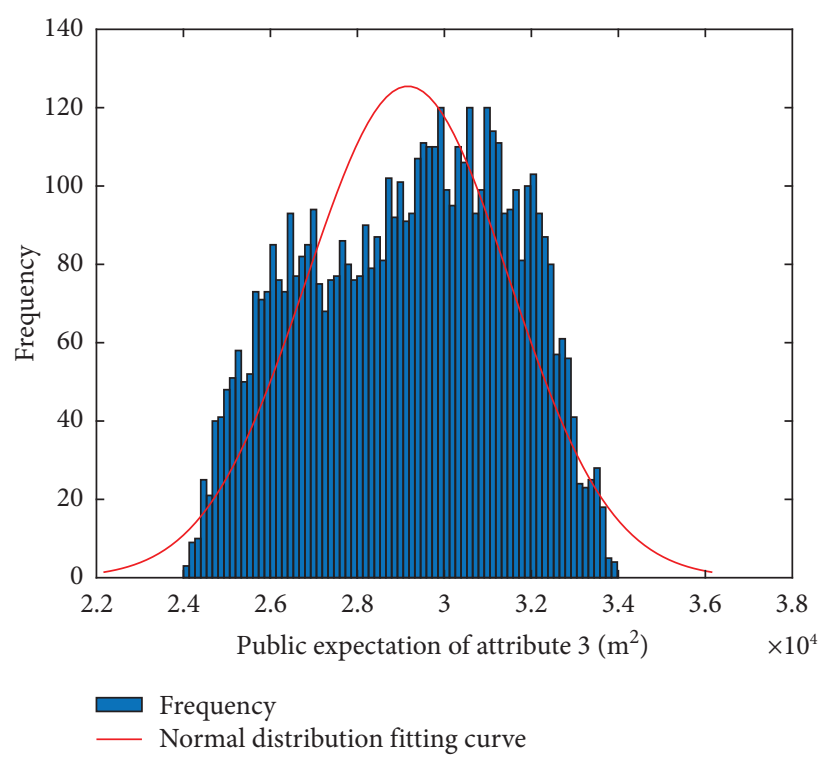

FIgURE 3: Fitting curve for public expected values of attribute 3.

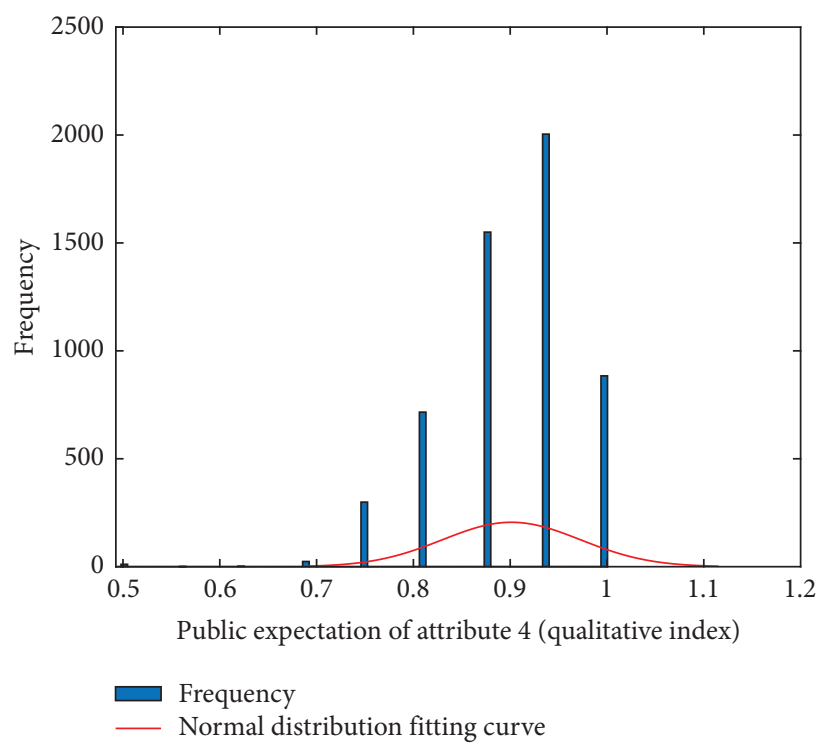

FIGURE 4: Fitting curve for public expected values of attribute 4. 
TABLE 7: Results of public expectation reference points for different attributes.

\begin{tabular}{lcccc}
\hline Attributes & $\begin{array}{c}\text { Average distance between the station } \\
\text { and the population gathering area } \\
\text { along the line }(\mathrm{m})\end{array}$ & $\begin{array}{c}\text { Estimated } \\
\text { construction time of } \\
\text { the project (months) }\end{array}$ & $\begin{array}{c}\text { Construction-enclosed } \\
\text { public areas }\left(\mathrm{m}^{2}\right)\end{array}$ & $\begin{array}{c}\text { Dust and sand } \\
\text { treatment } \\
\text { effect } \\
(\text { qualitative index) }\end{array}$ \\
\hline Statistical distribution & Normal distribution $N\left(446.0,74.41^{2}\right)$ & $\begin{array}{c}\text { Normal distribution } \\
N\left(69.49,8.48^{2}\right)\end{array}$ & $\begin{array}{c}\text { Normal distribution } N \\
\left(28990,2899^{2}\right)\end{array}$ & $\begin{array}{c}\text { Normal distribution } \\
N\left(0.75,0.15^{2}\right)\end{array}$ \\
\hline $\begin{array}{l}\text { Comprehensive ambiguity } \\
\text { of the expectations }\end{array}$ & 12.34 & 1.99 & 1006.21 \\
\hline Attribute reference point & {$[433.67,458.34]$} & {$[67.50,71.48]$} & {$[27983.79,29996.21]$} & {$[0.69,0.81]$} \\
\hline
\end{tabular}

TABLE 8: Normalized attribute reference points and attribute values for different alternatives.

\begin{tabular}{lcccc}
\hline Alternative & $\begin{array}{c}\text { Average distance between the station } \\
\text { and the population gathering area } \\
\text { along the line }(\mathrm{m})\end{array}$ & $\begin{array}{c}\text { Estimated construction } \\
\text { time of the project } \\
(\text { months })\end{array}$ & $\begin{array}{c}\text { Construction-enclosed } \\
\text { public areas }\left(\mathrm{m}^{2}\right)\end{array}$ & $\begin{array}{c}\text { Dust and sand treatment } \\
\text { effect }(\text { qualitative index) }\end{array}$ \\
\hline 1 & {$[1.0000,1.0000]$} & {$[0.0458,0.7137]$} & {$[0.0318,0.2734]$} & {$[0.3243,1.0000]$} \\
2 & {$[0.6182,0.6182]$} & {$[0.6183,1.0000]$} & {$[0.4943,1.0000]$} & {$[1.0000,1.0000]$} \\
3 & {$[0.9532,0.9532]$} & {$[0.3321,0.7137]$} & {$[0.0318,0.4179]$} & {$[0.3243,1.0000]$} \\
$\begin{array}{l}\text { Attribute } \\
\text { reference points }\end{array}$ & {$[0.0000,0.1922]$} & {$[0.0000,0.3798]$} & {$[0.0000,0.4353]$} & {$[0.0000,0.6486]$} \\
\hline
\end{tabular}

$$
\mathrm{VM}=\left[\begin{array}{llll}
0.8287 & 0.2070 & 0.0000 & 0.2164 \\
0.4719 & 0.4752 & 0.3587 & 0.3983 \\
0.7864 & 0.2070 & 0.0000 & 0.2164
\end{array}\right]
$$

The value range of the attribute weights can be determined using equation (9) based on the conversion between linguistic variables and interval numbers: $\omega_{1} \in[0.24,0.55]$; $\omega_{2} \in[0.07,0.26] ; \omega_{3} \in[0.10,0.34] ; \omega_{4} \in[0.17,0.44]$. Attribute weights can be determined using Model (10), $\omega_{1}=0.42 ; \omega_{2}=0.07 ; \omega_{3}=0.34 ; \omega_{4}=0.17$.

Based on the attribute prospect value and attribute weights, the comprehensive prospect value of each alternative can be obtained using equation (11), where $V_{1}=0.3994, V_{2}=0.4211$, and $V_{3}=0.3816$. The ranking of three alternatives is $V_{2}>V_{1}>V_{3}$. Therefore, $V_{2}$ is the optimal alternative.

\section{Comparison of Methods and Sensitivity Analysis}

5.1. Comparison of Methods. To verify the effectiveness of the proposed approach, we introduce two existing decisionmaking methods. The first method is the double-reference point decision-making method based on the prospect theory [42]. The second method is the TOPSIS method [43]. In the two mentioned methods, positive and negative ideal points are set as reference points used as the basis of the alternative evaluation. The positive and negative reference points of attribute $j$ are defined as $\widetilde{r}_{j}^{*+}$ and $\widetilde{r}_{j}^{*-}$, respectively. Based on the prospect theory and TOPSIS method, the comparison between the attribute value of the alternative and the corresponding reference points is analyzed, and the evaluation value of each alternative is obtained. In the double-reference point decision-making method based on the prospect theory, the maximum and minimum values of public expectation are taken as positive and negative reference points.

Public expectations obey the normal distribution; therefore, the maximum and minimum values of public expectations can be obtained using the three-sigma $(3 \sigma)$ theorem of normal distribution [44]. For attribute $j$, the maximum and minimum values of public expectations are obtained using the $3 \sigma$ theorem of normal distribution, denoted by $\mu\left(\bar{r}_{j}^{k}\right)+3 \sigma\left(\bar{r}_{j}^{k}\right)$ and $\mu\left(\bar{r}_{j}^{k}\right)-3 \sigma\left(\bar{r}_{j}^{k}\right)$, respectively. According to Definitions 1 and 2, the conversion values of linguistic variables or uncertain linguistic variables are in the range $[0,1]$. In the conversion crisp values' distribution of linguistic variables or uncertain linguistic variables, in order to ensure the maximum and minimum values, we meet the range requirements in this type of distribution; we define the maximum and minimum values as follows: if $\mu\left(\bar{r}_{j}^{k}\right)+3 \sigma\left(\bar{r}_{j}^{k}\right)>1$, we set maximum value as 1 ; if $\mu\left(\bar{r}_{j}^{k}\right)-3 \sigma\left(\bar{r}_{j}^{k}\right)<0$, we set minimum value as 0 . For the other scenarios, the maximum and minimum values are set as $\mu\left(\bar{r}_{j}^{k}\right)+3 \sigma\left(\bar{r}_{j}^{k}\right)$ and $\mu\left(\bar{r}_{j}^{k}\right)-3 \sigma\left(\bar{r}_{j}^{k}\right)$. To satisfy the calculation need of prospect value, we set the positive and negative reference points of the attribute as interval numbers with equal upper and lower limits, expressed as $\widetilde{r}_{j}^{*+}=\left[\left(\mu\left(\bar{r}_{j}^{k}\right)+\right.\right.$ $\left.\left.3 \sigma\left(\bar{r}_{j}^{k}\right)\right),\left(\mu\left(\bar{r}_{j}^{k}\right)+3 \sigma\left(\bar{r}_{j}^{k}\right)\right)\right] \quad$ and $\tilde{r}_{j}^{*-}=\left[\left(\mu\left(\bar{r}_{j}^{k}\right)-3 \sigma\left(\bar{r}_{j}^{k}\right)\right)\right.$, $\left.\left(\mu\left(\bar{r}_{j}^{k}\right)-3 \sigma\left(\bar{r}_{j}^{k}\right)\right)\right]$. In the TOPSIS method, we set the positive and negative ideal points according to the maximum and minimum values of each attribute in all alternatives. For example, the positive and negative reference points of attribute $j$ are, respectively, expressed as $\tilde{r}_{j}^{*+}=\left[\max _{i=1,2, \ldots, M} y_{j}^{i U}, \max _{i=1,2, \ldots, M} y_{j}^{i U}\right] \quad$ and $\widetilde{r}_{j}^{*-}=\left[\min _{i=1,2, \ldots, M} y_{j}^{i L}, \min _{i=1,2, \ldots, M} y_{j}^{i L}\right] . \quad$ The alternative ranking results of different decision methods are listed in Table 9.

According to Table 9, the alternative ranking results corresponding to the existing methods proposed are 
TABLE 9: Alternative ranking results of different decision methods.

\begin{tabular}{|c|c|c|c|}
\hline Methods & $\begin{array}{c}\text { Attribute } \\
\text { reference points }\end{array}$ & Decision results & $\begin{array}{l}\text { Ranking of } \\
\text { the alternatives }\end{array}$ \\
\hline $\begin{array}{l}\text { Double-reference point decision-making } \\
\text { method based on prospect theory }\end{array}$ & $\begin{array}{l}\widetilde{r}_{1}^{*+}=[222.77,222.77], \widetilde{r}_{2}^{*+}=[44.05,44.05], \\
\widetilde{r}_{3}^{*+}=[20293.00,20293.00], \widetilde{r}_{4}^{*+}=[1.00,1.00] \\
\widetilde{r}_{1}^{*-}=[669.23,669.23], \widetilde{r}_{2}^{*-}=[94.93,94.93] \\
\widetilde{r}_{3}^{*-}=[37687.00,37687.00], \widetilde{r}_{4}^{*-}=[0.00,0.00]\end{array}$ & $\begin{array}{l}V_{1}=-0.1738 \\
V_{2}=-0.0983 \\
V_{3}=-0.1654\end{array}$ & $V_{2}>V_{3}>V_{1}$ \\
\hline TOPSIS & $\begin{array}{l}\widetilde{r}_{1}^{*+}=[330.00,330.00], \widetilde{r}_{2}^{*+}=[61.00,61.00] \\
\tilde{r}_{3}^{*+}=[25373.00,25373.00], \widetilde{r}_{4}^{*+}=[0.875,0.875] \\
\widetilde{r}_{1}^{*-}=[379.00,379.00], \widetilde{r}_{2}^{*-}=[71.00,71.00] \\
\tilde{r}_{3}^{*-}=[29849.00,29849.00], \widetilde{r}_{4}^{*-}=[0.75,0.75]\end{array}$ & $\begin{array}{l}V_{1}=0.5719 \\
V_{2}=0.4772 \\
V_{3}=0.5564\end{array}$ & $V_{1}>V_{3}>V_{2}$ \\
\hline The proposed method & $\begin{array}{l}\widetilde{r}_{1}^{*}=[433.67,458.34], \widetilde{r}_{2}^{*}=[67.50,71.48] \\
\widetilde{r}_{3}^{*}=[27983.79,29996.21], \widetilde{r}_{4}^{*}=[0.69,0.81]\end{array}$ & $\begin{array}{l}V_{1}=0.3994 \\
V_{2}=0.4211 \\
V_{3}=0.3816\end{array}$ & $V_{2}>V_{1}>V_{3}$ \\
\hline
\end{tabular}

inconsistent with the results obtained in this study. The main reason for the inconsistency of decision results is that the reference point setting in each decision method is different.

The setting principle of reference points for the two existing methods is that reference points are obtained according to the public expectation or the attribute value of the alternative. The setting principle for the reference points used in the two existing methods is relatively simple, but it does not consider the characteristics of public expectations. For decision-making activities in major public affairs, public expectations must be fully considered to ensure the effectiveness of the decision-making results. Therefore, public expectations must be considered when setting reference points.

Based on the above analysis, we develop the setting principle for reference points by considering public expectations. First, the information on public expectations is discrete and has the characteristics of a normal distribution; thus, the mean value of public expectations is taken as the standard setting for the reference point so that the reference point can effectively reflect the expectations of the public group. Second, due to the uncertainty of the expectation evaluation by public individuals, the expected value is usually expressed in an interval number, which reflects the ambiguity of public expectations. The comprehensive expected ambiguity of the public is used to represent the uncertain characteristics of public expectations. The reference point is set by the mean value of public expectations and the comprehensive expected ambiguity of the public to better reflect the actual situation of public expectation expression. The results of the reference points are presented as interval numbers. The value of the reference points reflects the expectations of the public group and considers the uncertainty of the public evaluation.

If an attribute value in interval form falls within the range of the corresponding reference points in whole or in part, we consider that part of the attribute value that falls within the range of the reference points exactly meets public expectations, which means that the prospect value for this part of the attribute is zero. Therefore, when the prospect value is calculated based on the interval reference point, the inclusion or cross relationship between the attribute interval and corresponding reference point interval should be considered. For example, Table 8 indicates that the normalized values of attribute 3 for alternatives 1 and 3 are $p_{13}=[0.0318,0.2734]$ and $p_{33}=[0.0318$, $0.4179]$, respectively. Moreover, $p_{13}$ and $p_{33}$ are not equal, and the normalized reference point for attribute 3 is $q_{3}=[0.0000,0.4353]$. It is apparent that $p_{13}$ and $p_{33}$ are entirely within the interval range of $q_{3}$. We can affirm that the prospect values of attribute 3 for alternatives 1 and 3 are both zero $\left(v_{13}=v_{33}=0\right)$. In addition, we use equations (7) and (8) and Table 8 to calculate the prospect values of $p_{13}$ and $p_{33}$; we can also obtain the same result. If we choose the double-reference point decision-making method to calculate the prospect value of $p_{13}$ and $p_{33}$, the results of the prospect value for $p_{13}$ and $p_{33}$ are $v_{13}=-0.7329$ and $v_{33}=-0.6732$, which is different from the result of the proposed method. Therefore, a different setting principle for the reference point leads to different decision-making results, explaining why the sorting results are different in Table 9. Therefore, if we need to set reference points for decision-making, we must set them according to the actual situation for the decision problem and decision requirements to guarantee the effectiveness of the decision results.

5.2. Sensitivity Analysis of the Reference Point Interval Range. According to the content above, the comprehensive ambiguity of public expectations is related to the interval range of attribute reference points, affecting the decision-making results. The interval adjustment coefficient of reference point $\theta(0 \leq \theta \leq 1)$ is introduced in the expression of reference points to study the relationship between the value range of the reference points and decision results further. The reference point of attribute $j$ is defined as $\widetilde{r}_{j}^{*}=\left[\widetilde{r}_{j}^{* L}, \widetilde{r}_{j}^{* U}\right]=\left[\mu\left(\bar{r}_{j}^{k}\right)-\theta c_{j}, \mu\left(\bar{r}_{j}^{k}\right)+\theta c_{j}\right]$. The comprehensive ambiguity of public expectations for each attribute $c_{j}$ is known. When the values of $\theta$ are $0,0.25,0.5,0.75$, and 1 , the corresponding value range of reference points changes 
TABle 10: Decision results for different conditions of reference points.

\begin{tabular}{|c|c|c|c|}
\hline$\theta$ & Reference points & Comprehensive prospect value & Alternatives ranking \\
\hline 0 & $\begin{array}{l}\widetilde{r}_{1}^{*}=[446.00,446.00], \widetilde{r}_{2}^{*}=[69.49,69.49] \\
\widetilde{r}_{3}^{*}=[28990.00,28990.00], \widetilde{r}_{4}^{*}=[0.75,0.75]\end{array}$ & $\begin{array}{l}V_{1}=0.4365 \\
V_{2}=0.6769 \\
V_{3}=0.4699\end{array}$ & $V_{2}>V_{3}>V_{1}$ \\
\hline 0.25 & $\begin{array}{l}\widetilde{r}_{1}^{*}=[442.92,449.09], \widetilde{r}_{2}^{*}=[69.00,70.00] \\
\widetilde{r}_{3}^{*}=[28738.45,29241.55], \widetilde{r}_{4}^{*}=[0.74,0.77]\end{array}$ & $\begin{array}{l}V_{1}=0.4138 \\
V_{2}=0.6068 \\
V_{3}=0.4442\end{array}$ & $V_{2}>V_{3}>V_{1}$ \\
\hline 0.50 & $\begin{array}{l}\widetilde{r}_{1}^{*}=[439.83,452.17], \widetilde{r}_{2}^{*}=[68.51,70.50] \\
\widetilde{r}_{3}^{*}=[28486.90,29493.11], \widetilde{r}_{4}^{*}=[0.72,0.78]\end{array}$ & $\begin{array}{l}V_{1}=0.4104 \\
V_{2}=0.5425 \\
V_{3}=0.4231\end{array}$ & $V_{2}>V_{3}>V_{1}$ \\
\hline 0.75 & $\begin{array}{l}\widetilde{r}_{1}^{*}=[436.75,455.26], \widetilde{r}_{2}^{*}=[68.01,70.99] \\
\widetilde{r}_{3}^{*}=[28235.34,29744.66], \widetilde{r}_{4}^{*}=[0.71,0.80]\end{array}$ & $\begin{array}{l}V_{1}=0.4141 \\
V_{2}=0.4827 \\
V_{3}=0.4066\end{array}$ & $V_{2}>V_{1}>V_{3}$ \\
\hline 1 & $\begin{array}{l}\widetilde{r}_{1}^{*}=[433.67,458.34], \widetilde{r}_{2}^{*}=[67.50,71.48] \\
\widetilde{r}_{3}^{*}=[27983.79,29996.21], \widetilde{r}_{4}^{*}=[0.69,0.81]\end{array}$ & $\begin{array}{l}V_{1}=0.3994 \\
V_{2}=0.4211 \\
V_{3}=0.3816\end{array}$ & $V_{2}>V_{1}>V_{3}$ \\
\hline
\end{tabular}

accordingly. The decision results for different conditions of reference points are presented in Table 10.

As listed in Table 10, when the interval adjustment coefficient of the reference points increases gradually, the interval range of the reference points for different attributes is also constantly enlarged, so the alternative ranking results are not the same. As observed in Table 10, if $\theta \in[0,0.5]$, the sorting result is $V_{2}>V_{3}>V_{1}$. Moreover, if $\theta \in[0.75,1]$, the sorting result is $V_{2}>V_{1}>V_{3}$. In addition, the alternative ranking results in Table 10 with the continuous expansion of the interval for reference points indicate that the comprehensive prospect value of each alternative also constantly decreases. In addition, the differentiation degree of the comprehensive prospect value between alternatives also gradually decreases. Therefore, to ensure the effectiveness of setting attribute reference points, we must consider the influence of the interval range of the reference points for the decision results to reduce the difficulty of decision-making and improve the accuracy of decision results.

\section{Conclusion}

This paper proposed a new decision-making approach for a mixed multiattribute decision-making problem with unknown attribute weights. The advantages of this approach are summarized as follows. First, the reference point for each attribute is set based on the distribution and comprehensive ambiguity of public expectations, making the attribute reference points better reflect the public's expected group opinions and expectation uncertainty. The effectiveness of the decision result is guaranteed. Second, in solving the attribute weights, the attribute importance given by the public is used to determine the value range of the attribute weights so that the weighting results are in accordance with public opinions, making the results of the attribute weight more acceptable. Then, the exact values of the attribute weights are determined to maximize the attribute information deviation of all the alternatives, improving the discrimination of alternatives. Third, each alternative is evaluated based on the prospect theory to satisfy the calculation needs of the prospect value. The different expression forms of the attribute information and reference point are unified, and normalization is performed. The operation above can eliminate the influence of the expression form and dimension on decision-making, making the decision operations smoother.

The proposed approach also has certain limitations. First, in the actual decision-making process, the decisionmaking scenarios in some decision-making problems are not static. Changes in the decision-making scenarios easily cause decision risk, which negatively affects the decision activity. Our proposed approach does not consider dynamic decision scenarios, so the proposed approach must be further expanded and improved, making it suitable for public-participation decision-making problems under changing scenarios. Second, according to the setting principle of reference points, the interval range of the attribute reference points affects the decision-making results. The interval range of the attribute reference points is large, and the discrimination of the evaluation results for different alternatives is less obvious. Because the interval range of attribute reference points is set by the comprehensive ambiguity of public expectations, if the dispersion degree of public expectations is overly high (i.e., the comprehensive ambiguity of public expectations is overly high), the interval range of attribute reference points is also set over wide corresponding values. This outcome may lead to a lack of differentiation in the decision results. Therefore, to ensure the effectiveness of the decision-making results, reasonable interval ranges must be set for attribute reference points according to the characteristics of public expectation information, which is also worth an in-depth study.

\section{Data Availability}

The data used to support the findings of this study are included within the manuscript. 


\section{Conflicts of Interest}

The authors declare no conflicts of interest.

\section{Acknowledgments}

This research was funded by the National Natural Science Foundation of China (no. 71902058), Natural Science Foundation of Hunan Province (nos. 2018JJ3617 and 2021JJ41088), Social Science Foundation of Hunan Province (no. 19YBQ113), Scientific Research Foundation of Hunan Education Department (nos. 18B484, 19A06, and 20B155), and Social Science Achievements Appraisal Committee Foundation of Hunan Provincial Department (no. XSP21YBC218).

\section{References}

[1] S. Song, Z. Guo, and X. Wang, "Retracted article: the correlation between social transformation economic risk and internet public opinion," Behaviour \& Information Technology, vol. 40, no. 7, pp. 723-733, 2020.

[2] W. Chen, F. Tu, and P. Zheng, "A transnational networked public sphere of air pollution: analysis of a Twitter network of PM2.5 from the risk society perspective," Information, Communication \& Society, vol. 20, no. 7, pp. 1005-1023, 2017.

[3] X. Yao, J. He, and C. Bao, "Public participation modes in China's environmental impact assessment process: an analytical framework based on participation extent and conflict level," Environmental Impact Assessment Review, vol. 84, p. 106400, 2020.

[4] X. Zhang, J. G. Xu, and Y. Ju, "Public participation in NIMBY risk mitigation: A discourse zoning approach in the Chinese context," Land Use Policy, vol. 77, pp. 559-575, 2018.

[5] T. Webler and S. Tuler, "Four decades of public participation in risk decision making," Risk Analysis, vol. 41, no. 3, pp. 503-518, 2021.

[6] J. P. Voß and N. Amelung, "Innovating public participation methods: Technoscientization and reflexive engagement," Social Studies of Science, vol. 46, no. 5, pp. 749-772, 2016.

[7] A. M. Ríos, B. Benito, and F. Bastida, "Factors explaining public participation in the central government budget process," Australian Journal of Public Administration, vol. 76, no. 1, pp. 48-64, 2017.

[8] Y. Zhou, L. Hou, Y. Yang, H.-Y. Chong, and S. Moon, “A comparative review and framework development on public participation for decision-making in Chinese public projects," Environmental Impact Assessment Review, vol. 75, pp. 79-87, 2019.

[9] T. H. You, J. Zhang, and Z. P. Fan, "Multi-attribute online review decision making method based on sentiment analysis and evidence theory," Journal of Systems \&. Management, vol. 28, no. 3, pp. 536-544, 2019, in Chinese.

[10] R. L. Charney, T. Rebmann, P. Dalawari, and A. Endrizal, "Public expectations of hospitals to provide resources and services to the uninjured during disasters: A qualitative study," Health Security, vol. 14, no. 6, pp. 389-396, 2016.

[11] A. Yildiz, E. Ayyildiz, A. Taskin Gumus, and C. Ozkan, "A framework to prioritize the public expectations from water treatment plants based on trapezoidal type-2 fuzzy ahp method," Environmental Management, vol. 67, no. 3, pp. 439-448, 2020.
[12] Z. Zhang, Y. Gao, and Z. L. Li, "Consensus reaching for social network group decision making by considering leadership and bounded confidence," Knowledge-Based Systems, vol. 204, pp. 1-12, 2020.

[13] J. J. Zhu, Z. Z. Ma, H. H. Wang, and Y. Chen, "Risk decisionmaking method using interval numbers and its application based on the prospect value with multiple reference points," Information Sciences, vol. 12, no. 3, pp. 385-386, 2017.

[14] X. Li and X. Chen, "Value determination method based on multiple reference points under a trapezoidal intuitionistic fuzzy environment," Applied Soft Computing, vol. 63, pp. 39-49, 2018.

[15] J. Gao, Z. Xu, and H. Liao, "A dynamic reference point method for emergency response under hesitant probabilistic fuzzy environment," International Journal of Fuzzy Systems, vol. 19, no. 5, pp. 1261-1278, 2017.

[16] C. H. Li, W. Li, M. J. Li et al., "Target-oriented model and approach for attribute value evaluation with multiple reference points," Chinese Journal of Management Science, vol. 25, no. 7, pp. 163-175, 2017, in Chinese.

[17] E. Mastrocinque, F. J. Ramírez, A. Honrubia-Escribano, and D. T. Pham, "An AHP-based multi-criteria model for sustainable supply chain development in the renewable energy sector," Expert Systems with Applications, vol. 150, pp. 1-17, 2020.

[18] L. Chen, Z. Li, and X. Deng, "Emergency alternative evaluation under group decision makers: a new method based on entropy weight and dematel," International Journal of Systems Science, vol. 51, no. 3, pp. 570-583, 2020.

[19] X. K. Wang, Y. T. Wang, J. Q. Wang, P. F. Cheng, and L. Li, “A TODIM-PROMETHEE II based multi-criteria group decision making method for risk evaluation of water resource carrying capacity under probabilistic linguistic $Z$-number circumstances," Mathematics, vol. 8, no. 7, p. 1190, 2020.

[20] Y. Liu, Y. Dong, H. Liang, F. Chiclana, and E. HerreraViedma, "Multiple attribute strategic weight manipulation with minimum cost in a group decision making context with interval attribute weights information," IEEE Transactions on Systems, Man, and Cybernetics: Systems, vol. 49, no. 10, pp. 1981-1992, 2018.

[21] F. Meng, C. Tan, and X. Chen, "An approach to Atanassov's interval-valued intuitionistic fuzzy multi-attribute decision making based on prospect theory," International Journal of Computational Intelligence Systems, vol. 8, no. 3, pp. 591-605, 2015.

[22] N. Zarbakhshnia, Y. Wu, K. Govindan, and H. Soleimani, “A novel hybrid multiple attribute decision-making approach for outsourcing sustainable reverse logistics," Journal of Cleaner Production, vol. 242, Article ID 118461, 2020.

[23] J. J. H. Liou, Y. C. Chuang, E. K. Zavadskas, and G. H. Tzeng, "Data-driven hybrid multiple attribute decision-making model for green supplier evaluation and performance improvement," Journal of Cleaner Production, vol. 241, Article ID 118321, 2019.

[24] Y. H. Pan and X. L. Geng, "Hybrid multiple attribute decision making approach based on Mo-RVIKOR," Chinese Journal of Management Science, vol. 27, no. 12, pp. 143-151, 2019.

[25] M. Akram and D. Shumaiza, "Multi-criteria decision making based on q-rung orthopair fuzzy promethee approach," Iranian Journal of Fuzzy Systems, vol. 18, no. 5, pp. 107-127, 2021.

[26] C. Jana, G. Muhiuddin, and M. Pal, "Multi-criteria decision making approach based on SVTrN Dombi aggregation functions," Artificial Intelligence Review, vol. 54, no. 5, pp. 3685-3723, 2021. 
[27] C. Jana, G. Muhiuddin, and M. Pal, "Multiple-attribute decision making problems based on SVTNH methods," Journal of Ambient Intelligence and Humanized Computing, vol. 11, no. 9, pp. 3717-3733, 2020.

[28] C. Jana, G. Muhiuddin, and M. Pal, "Some Dombi aggregation of $Q$-rung orthopair fuzzy numbers in multiple-attribute decision making," International Journal of Intelligent Systems, vol. 34, no. 12, pp. 3220-3240, 2019.

[29] G. Shahzadi, G. Muhiuddin, M. Arif Butt, and A. Ashraf, "Hamacher interactive hybrid weighted averaging operators under fermatean fuzzy numbers," Journal of Mathematics, vol. 2021, no. 10, 17 pages, Article ID 5556017, 2021.

[30] K. Zhang, J. Zhan, and X. Wang, “TOPSIS-WAA method based on a covering-based fuzzy rough set: An application to rating problem," Information Sciences, vol. 539, pp. 397-421, 2020.

[31] S. F. Huang, "Using Linguistic VIKOR and fuzzy cognitive maps to select virtual reality games development project," Mathematics, vol. 9, no. 11, p. 1253, 2021.

[32] M. Akram, A. Luqman, and C. Kahraman, "Hesitant pythagorean fuzzy ELECTRE-II method for multi-criteria decision-making problems," Applied Soft Computing, vol. 108, Article ID 107479, 2021.

[33] C. Erdin and G. Ozkaya, “Turkey's 2023 energy strategies and investment opportunities for renewable energy sources: Site selection based on ELECTRE," Sustainability, vol. 11, no. 7, Article ID 2136, 2019.

[34] T. Wang, H. Li, X. Zhou, D. Liu, and B. Huang, "Three-way decision based on third-generation prospect theory with $Z$ numbers," Information Sciences, vol. 569, pp. 13-38, 2021.

[35] Z. J. Du, S. M. Yu, H. Y. Luo, and X. D. Lin, "Consensus convergence in large-group social network environment: coordination between trust relationship and opinion similarity," Knowledge-Based Systems, vol. 217, Article ID 106828, 2021.

[36] J. Wu, F. Chiclana, H. Fujita, and E. Herrera-Viedma, “A visual interaction consensus model for social network group decision making with trust propagation," Knowledge-Based Systems, vol. 122, pp. 39-50, 2017.

[37] L. X. Chen and N. F. Luo, "Pythagorean fuzzy multi-criteria decision-making based on prospect theory," Systems Engineering Theory \& Practice, vol. 40, no. 3, pp. 726-735, 2020, in Chinese.

[38] Z. S. Xu, Linguistic Decision Making, Springer-Verlag, Berlin, Germany, 2012.

[39] R. E. Moore, Methods and Applications of Interval Analysis, Prentice-Hall, Hoboken, NY, USA, 1979.

[40] R. R. Ren, W. W. Li, M. Zhao, and X. Li, "A large group decision making method based on public evaluation," Management Review, vol. 30, no. 10, pp. 238-247, 2018.

[41] L. Wang, Y. M. Wang, and L. Martínez, "A group decision method based on prospect theory for emergency situations," Information Sciences, vol. 418-419, pp. 119-135, 2017.

[42] Y. Wu, C. Xu, and T. Zhang, "Evaluation of renewable power sources using a fuzzy MCDM based on cumulative prospect theory: a case in China," Energy, vol. 147, pp. 1227-1239, 2018.

[43] M. M. Salih, B. B. Zaidan, A. A. Zaidan, and M. A. Ahmed, "Survey on fuzzy TOPSIS state-of-the-art between 2007 and 2017," Computers \& Operations Research, vol. 104, pp. 207227, 2019.

[44] H. Xiao, Y. Zhang, X. Liu, H. Yin, P. Liu, and D. C. Liu, "A rapid ultrasound vascular disease screening method using PauTa Criterion," Journal of Physics: Conference Series, vol. 1769, Article ID 012009, 2021. 